\title{
ANALISIS HASIL BELAJAR PRAKTIK PEMBUATAN BUSANA WANITA MENGGUNAKAN SYNDICATE GROUP DISCUSSION
}

\author{
Agus Hery Supadmi Irianti ${ }^{1 *}$, Nurul Aini ${ }^{2}$, Nur Endah Purwaningsih ${ }^{3}$, Rizki Rahayuning $^{2}$ \\ Tyas $^{4}$, Jeihan Amalia ${ }^{5}$ \\ Universitas Negeri Malang ${ }^{1,2,3,4,5}$ \\ Agushery_um52@yahoo.co.id ${ }^{l}$
}

\begin{abstract}
Abstrak.
Output Pendidikan Tata Busana adalah guru bidang busana, sehingga mahasiswa sebagai calon guru yang belajar Teknik Pembuatan Busana Wanita (TPBW) dituntut untuk dapat menginformasikan pembuatan busana wanita kepada siswanya dengan benar. TPBW adalah mata kuliah keahlian kejuruan yang wajib ditempuh, dan dilaksanakan pembelajarannya melalui praktikum di laboratorium produksi busana. Penelitian ini sangat penting dilakukan karena selama ini metode pembelajaran yang diterapkan pada mata kuliah praktik kebanyakan menerapkan metode penugasan, demonstrasi dan latihan kerja saja. Pemilihan syndicate group discussion belum pernah diterapkan untuk praktikum pembuatan busana wanita. Padahal metode ini dapat memperkecil atau meminimalisir kesalahankesalahan pada saat praktik. Penelitian ini bertujuan untuk menganalisis hasil belajar praktik pembuatan busana wa-nita menggunakan metode syndicate group discussion. Jenis penelitian ini adalah penelitian diskriptif dengan pendekatan kuantitatif. Hasil penelitian menunjukkan syndicate group discussion dapat membantu mahasiswa lebih mudah belajar praktik pembuatan busana yaitu pada ranah belajar afektif, kognitif dan psikomotor. Saran dalam penelitian ini adalah: bagi pengampu mata kuliah praktik sebaiknya menggunakan syndicate group discussion agar dapat mengurangi kesalahan pada proses belajar praktik
\end{abstract}

Kata Kunci: Hasil Belajar, praktik pembuatan busana wanita, syndicate group discussion

\section{Pendahuluan}

Output Pendidikan Tata Busana adalah guru bidang busana, sehingga mahasiswa sebagai calon guru dituntut untuk dapat menginformasikan pembuatan busana wanita kepada siswanya dengan benar. Terkait itulah mata kuliah TPBW bukan mengajarkan mahasiswa untuk terampil menjahit busana wanita, namun mengajarkan bagaimana siswa sebagai calon guru dapat menginformasikan pengetahuan dan keterampilan menjahit pada siswanya nanti. Diskripsi Mata Kuliah TPBW yaitu menelaah konsep membuat busana dan memproduksi blus, rok, gaun dan modifikasinya serta menganalisis mode busana wanita (Katalog TI, 2015).Pembelajaran yang seringkali ditemui pada mata kuliah praktik adalah pembuatan produk secara terbimbing berupa projek ataupun penugasan yang lebih memprioritaskan pada proses dan hasil produksi. Sementara kemampuan sebagai calon guru seringkali terabaikan. Hal ini dapat dilihat dari hasil pengamatan bahwa peran beberapa guru mata kuliah praktikum dalam memilih metode pembelajaran praktik adalah demonstrasi dan pelatihan kerja, penyampaian informasi praktikum juga disampaikan dalam bentuk ceramah yang memungkinkan pembelajaran berpusat pada guru.

Syndicate Group Discussion merupakan metode pembelajaran dengan teknik diskusi kelompok kecil, dimana tema yang didiskusikan antar kelompok kecil dalam satu kelas berbeda-beda. Keragaman tema diskusi dimungkinkan mahasiswa mendapat banyak wawasan pengetahuan hasil diskusi. Syndicate Group Discussion yang dilaksanakan sebelum praktikum merupakan ajang dis kusi yang membahas segala sesuatu yang akan dipraktikkan, diantaranya dalam menganalisis model busana, pecah pola busana wanita, pemilihan bahan, merancang bahan dan harga, sampai dengan langkah pembuatan busana. Melalui diskusi itulah diharapkan kekurangan atau kesalahan didiskusikan dengan memperbaiki berdasarkan masukan anggota kelompok diskusi juga anggota kelompok lainnya, sehingga pada saat praktik nanti akan berkurang. Menurut Notoatmodjo 2007, Pengetahuan adalah merupakan hasil dari tahu dan ini setelah orang melakukan penginderaan terhadap obyek tertentu. Penginderaan terjadi melalui panca indera manusia, yakni indera 
penglihatan, pendengaran, penciuman, rasa dan raba. Sebagaian besar pengetahuan manusia diperoleh melalui mata dan telinga. Faktor yang mempengaruhi pengetahuan dalam diri seseorang adalah: (1) pendidikan, (2) informasi, (3) sosial budaya dan ekonomi, (4) lingkungan, (5) pengalaman dan (6) usia. Pembelajaran menggunakan metode syndicate group discussion yang dilakukan sebelum prak tikum merupakan pendidikan, informasi dan pengalaman yang diperoleh siswa, sehingga pengetahuannya bertambah. Menurut Mursid (2013) Keefektivitasan syndicate group discusssion ditunjukkan oleh beberapa hasil penelitian. 1) hasil belajar mahasiswa dengan menggunakan model pembelajaran ini lebih efektif dibandingkan tanpa menggunakan model pembelajaran (konvensional) terhadap peningkatan kompetensi mahasiswa pada aspek afektif, kognitif, dan psikomotorik. 2) hasil belajar mahasiswa pada kelompok eksperimen dengan menggunakan model pembelajaran ratarata nilai lebih tinggi daripada hasil belajar pada kelompok mahasiswa pada pembelajaran konven-sional.3) dapat meningkatkan kompetensi mahasiswa di bidang praktik pada pembelajaran teknologi pemesinan secara bertahap. (R Mursid, 2013). Hasil penelitian yang lain menyatakan: terdapat pengaruh metode pembelajaran Syndicate group discussion terhadap pemahaman konsep matematika Siswa SMA Negeri 14 Pekanbaru (Istiarni, diakses 26 APRIL 2016) http://download. portal garuda.org/ Syndicate group discussion discussion merupakan metode diskusi kelompok kecil pada kelas dengan topik diskusi yang berbeda beda antara kelompok satu dengan kelompok lainnya. Tujuan diterapkannya syndicate group discussion discussion pada mata kuliah TPBW adalah untuk mendapatkan keragaman wawasan pengetahuan mahasiswa dalam menganalisis berbagai model busana pada sebagai materi praktikum sebelum mahasiswa melaksanakan praktik. Hal ini dilakukan untuk meminimalisisr kesalahan praktik pada pembuatan busana wanita

Hasil belajar adalah perubahan yang terjadi secara sadar, bersifat kontinyu dan fungsional setelah mengalami pengalaman dalam kegiatan pembelajaran (Slameto, 2003:4). Sudjana (2005: 22) menjelaskan bahwa hasil belajar adalah kemampuan yang dimiliki siswa setelah ia menerima hasil belajarnya. Sedangkan penilaian hasil belajar adalah proses pemberian nilai terhadap hasil belajar yang dicapai siswa dalam kriteria tertentu. Hasil belajar pada hakekatnya adalah perubahan tingkah laku sebagai proses dari hasil belajar mengajar. Adanya hasil belajar, maka orang dapat me- ngetahui seberapa jauh siswa dapat menangkap memahami memiliki materi atas pelajaran tertentu. Berdasarkan hasil belajar inilah seorang pendidik dapat menentukan strategi belajar mengajar yang lebih baik (Purwanto, 2010:42). Indikator hasil belajar yang dikembangkan dari Bloom meliputi 3 ranah yaitu ranah kognitif, ranah afektif dan ranah psikomotor (Burhan, 1988:42). Indikator hasil belajar dari ketiga ranah tersebut dapat dipaparkan sebagai berikut. Ranah kognitif meliputi: (1)pengetahuan (knowledge), (2) pemahaman (comprehension),(3) penerapan (application) (4) analisis (analysis), (5) menciptakan, membangun (synthesis). Ranah afektif meliputi: (1) pene-rimaan (receiving) (2) men-jawab/menanggapi (responding), (3) peni laian (valuing), (4) organisasi (organization), (5) menentukan ciri-ciri nilai (characterizat ion by a value or value complex). Ranah psikomotor meliputi: (1) gerakan pokok (fundamental movement), (2) gerakan umum (generic movement), (3) gerakan ordinat (ordinative movement), (4) gerakan kreativ (creative movement). Sedangkan Dimyati dan Mudjiono (2002: 174) menjelaskan bahwa ranah-ranah tersebut adalah sebagai berikut: (1) ranah kognitif berkaitan dengan hasil belajar intelektual yang terdiri dari 5 aspek, yaitu pengetahuan atau ingatan, pemahaman, aplikasi, analisis dan evaluasi; ranah afektif berkenaan dengan sikap yang terdiri dari 5 aspek, yaitu: penerimaan, jawaban atau reaksi, penilaian, organisasi dan internalisasi; ranah psikomotor berkenaan dengan hasil keterampilan dan kemampuan bertindak me-liputi: gerakan releks, keteraturan gerakan dasar, keharmonisan atau ketepatan, gerakan keterampilan kompleks dan gerakan ekspresif.

Tujuan penelitian ini untuk mengetahui analisis hasil belajar praktik pembuatan busana wanita dengan menggunakan metode Syndicate group discussion

\section{Metode}

Penelitian ini adalah penelitian dengan pendekatan kuantitatif. Teknik analisis yang digunakan adalah analisis deskriptif dengan persentase. Populasi dalam penelitian ini adalah mahasiswa angkatan tahun 2014 sejumlah 20 mahasiswa yang telah melaksanakan praktikum Teknik pembuatan busana wanita (TPBW) dengan metode Syndicate Group Discussion Teknik sampling menggunakan sampel jenuh, karena mahasiswa diambil keseluruhan. Variabel dalam penelitian 
ini adalah Efektivitas Syndicate group discussion pada pembelajaran praktikum pembuatan busana wanita.

\subsection{Metode Pengumpulan Data}

Metode pengumpulan data yang digunakan dalam penelitian ini adalah dokumen, yaitu untuk melihat nilai praktik sedangkan metode observasi digunakan untuk mengambil data tentang pelaksanaan syndicate group discussion. Menggunakan angket.

\subsection{Metode Analisis Data}

Metode analisis data yang digunakan untuk mengungkap efektivitas penggunaan syndicate group discussion pada perkuliahan praktik pembuatan busana wanita meng-gunakan analisis deskriptif persentase karena hanya akan mendeskripsikan efektifitas penggunaan syndivate group pada mata kuliah praktik.serta mengungkap hasil belajarnya.

\section{Hasil dan Pembahasan}

\section{A. Hasil Deskripsi Data Tentang Analisis Hasil} Belajar Praktik menggunakan Metode Syndicate Group Discussion

Data Tentang Analisis Hasil Belajar Praktik menggunakan Metode Syndicate Group Discussion terdiri dari :

\section{Analisis Hasil Belajar Praktik Aspek Kognitif}

Dari data yang dikumpulkan mengenai aspek kognitif pembelajaran dengan menggunakan metode Syndicate Group Discussion yang terdiri dari 9 item pertanyaan dengan 4 alternatif jawaban, masing-masing pertanyaan memiliki 4 alternatif jawaban dengan nilai skor: SS( sangat setuju) nilai skor:4, S (setuju) nilai skor:3, KS (kurang Setuju) nilai skor:2, TS (Tidak Setuju) nilai skor:1.Data distribusi frekuensinya dilihat pada Tabel 1 berikut ini.

Tabel 1 Distribusi Frekuensi Analisis Hasil belajar Aspek Kognitif

\begin{tabular}{clcc}
\hline interval & \multicolumn{1}{c}{ Kategori } & f & $(\boldsymbol{\%})$ \\
\hline $585-720$ & Sangat efektif & 123 & 68,33 \\
$450-584$ & Efektif & 48 & 6,67 \\
$315-449$ & Kurang efektif & 4 & 2,22 \\
$180-314$ & Tidak efektif & 5 & 2,78 \\
Total(jml responden x 9) & 180 & $100 \%$ \\
\hline
\end{tabular}

Adapun grafik dapat dilihat pada gambar 1 .

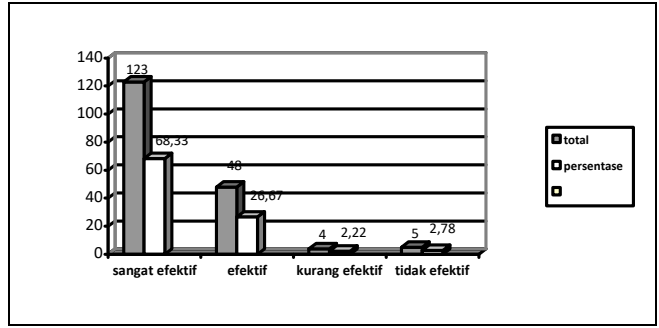

Gambar 1 Grafik analisis Hasil Belajar Praktik Aspek Kognitif

\section{Analisis Hasil Belajar Praktik Aspek Afektif.}

Dari data yang dikumpulkan mengenai aspek Afektif pembelajaran praktik dengan meng-gunakan metode Syndicate Group Discussion yang terdiri dari 8 item pertanyaan dengan 4 alternatif jawaban, masing-masing pertanyaan memiliki 4 alternatif jawaban dengan nilai skor: SS( sangat setuju) nilai skor:4, S (setuju) nilai skor:3, KS (kurang Setuju) nilai skor:2, TS (Tidak Se-tuju) nilai skor:1.

Data deskripsi Hasil belajar Aspek Afektif dapat dilihat pada distribusi frekuensinya. Data penyajian distribusi frekuensi dapat dilihat pada Tabel 2 berikut.

\section{Tabel 2 Distribusi Frekuensi Analisis Hasil belajar Aspek Afektif}

\begin{tabular}{clrr}
\hline interval & \multicolumn{1}{c}{ Kategori } & frek & \multicolumn{1}{c}{$(\boldsymbol{\%})$} \\
\hline $280-320$ & Sangat efektif & 100 & 62,50 \\
$240-279$ & Efektif & 56 & 35,00 \\
$200-239$ & Kurang efektif & 4 & 2,50 \\
$160-199$ & Tidak efektif & 0 & 0 \\
Total $($ jml responden x 8) & 160 & 100 \\
\hline
\end{tabular}

Adapun Grafik dapat dilihat pada gambar 2 berikut ini.

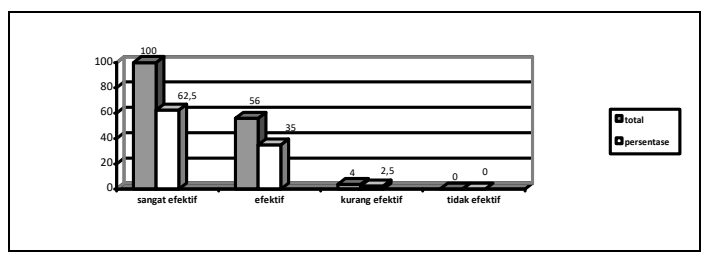

Gambar 2 Grafik analisis Hasil belajar praktik aspek Afektif 


\section{Analisis Hasil Belajar Praktik Aspek Psiko-motor.}

Dari data yang dikumpulkan mengenai aspek kognitif pembelajaran dengan meng-gunakan metode Syndicate Group Discu-ssion yang terdiri dari 9 item pertanyaan dengan 4 alternatif jawaban, masing-masing pertanyaan memiliki 4 alternatif jawaban dengan nilai skor: SS( sangat setuju) nilai skor:4, S (setuju) nilai skor:3, KS (kurang Setuju) nilai skor:2, TS (Tidak Setuju) nilai skor:1Data distribusi frekuensi dapat dilihat pada Tabel 3 ..

Tabel 3 Distribusi Frekuensi Analisis Hasil belajar Aspek Psikomotor

\begin{tabular}{clrr}
\hline interval & \multicolumn{1}{c}{ Kategori } & \multicolumn{1}{c}{ f } & \multicolumn{1}{c}{$(\mathbf{\%})$} \\
\hline $855-1040$ & Sangat efektif & 159 & 61,15 \\
$550-844$ & Efektif & 95 & 36,54 \\
$455-649$ & Kurang efektif & 5 & 1,92 \\
$260-454$ & Tidak efektif & 1 & 0,38 \\
Total(jml responden x 9) & 260 & 100,00 \\
\hline
\end{tabular}

Adapun Grafik Analisis Hasil Belajar Praktik aspek psikomotor dapat dilihat pada gambar 3 berikut ini.

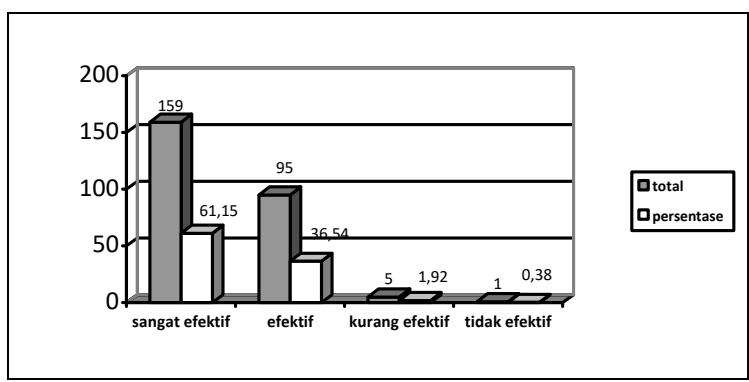

Gambar.3 Grafik analisis Hasil belajar praktik aspek Psikomotor

\section{Analisis Hasil Belajar Praktik Dengan Metode Syndicate Group Discussion}

Dari data yang dikumpulkan mengenai Hasil belajar dengan menggunakan metode Syndicate Group Discussion yang terdiri dari 30 item pertanyaan dengan 4 alternatif jawaban, masingmasing pertanyaan memiliki 4 alternatif jawaban dengan nilai skor: SS( sangat setuju) nilai skor:4, S (setuju) nilai skor:3, KS (kurang Setuju) nilai skor:2, TS (Tidak Setuju) nilai skor:1. Jumlah item. Data deskripsi Analisis Hasil Belajar Praktik Dengan Metode Syndicate Group Discussion dapat dilihat pada Tabel 4 berikut.
Tabel 4 Distribusi Analisis Hasil Belajar Praktik Dengan Metode Syndicate Group Discussion

\begin{tabular}{clrr}
\hline interval & \multicolumn{1}{c}{ Kategori } & f & \multicolumn{1}{c}{$(\boldsymbol{\%})$} \\
\hline $1950-2400$ & Sangat efektif & 382 & 63,66 \\
$1500-1949$ & Efektif & 199 & 33,17 \\
$1050-1499$ & Kurang efektif & 13 & 2,17 \\
$600-1049$ & Tidak efektif & 6 & \\
Total $($ jml responden x 9) & 600 & 100 \\
\hline
\end{tabular}

Adapun Grafik Analisis Hasil Belajar Praktik dengan Syndicate group disccusion dapat dilihat pada gambar 4 berikut ini.

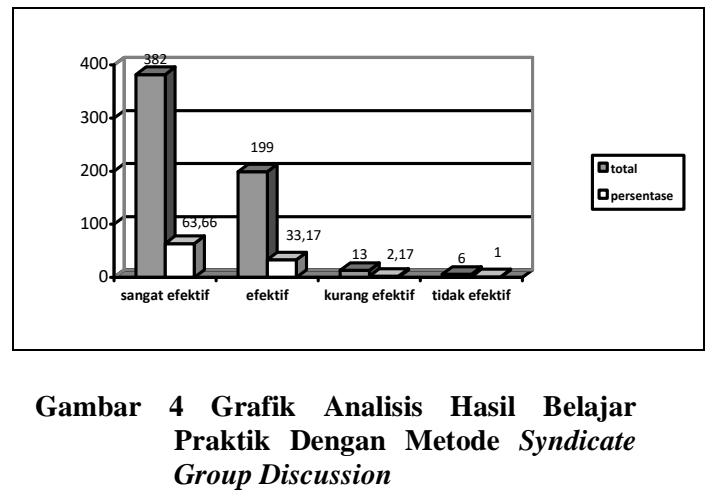

\section{B. Hasil Belajar Praktik Pembuatan Busana Wanita}

Hasil belajar praktik Pembuatan Busana wanita diambil dari dokumen hasil penilaian praktikum. Hasil penilaian ditabulasikan dalam skala likert dengan kategori, yaitu sangat memuaskan dengan skore 4 yaitu nilai A- dan A dan B+, Memuaskan dengan skore 3, yaitu nilai B dan B-, Cukup memuaskan dengan skore 2 yaitu nilai $\mathrm{C}+$ dan $\mathrm{C}$, dan tidak memuaskan dengan skore 1adalah $\mathrm{D}$ dan $\mathrm{E}$. Adapun hasil belajar praktik dapat dituliskan distribusi frekuensinya. Data penyajian distribusi frekuensi dapat dilihat pada Tabel 5 berikut ini.

Tabel 5 Distribusi Nilai Hasil Belajar Praktik

\begin{tabular}{clrr}
\hline interval & \multicolumn{1}{c}{ Kategori } & \multicolumn{1}{c}{ f } & \multicolumn{1}{c}{$(\boldsymbol{\%})$} \\
\hline $76-100$ & Sangat Memuaskan & 15 & 75,00 \\
$65-75$ & Memuaskan & 4 & 20,00 \\
$50-64$ & Kurang memuaskan & 1 & 5,00 \\
$<50$ & Tidak memuaskan & 0 & 0,00 \\
Total(jml responden x 9) & 600 & 100,00 \\
\hline
\end{tabular}

Adapun Grafik Analisis Hasil Belajar Praktik dengan Syndicate group disccusion dapat dilihat pada gambar 5 berikut ini. 


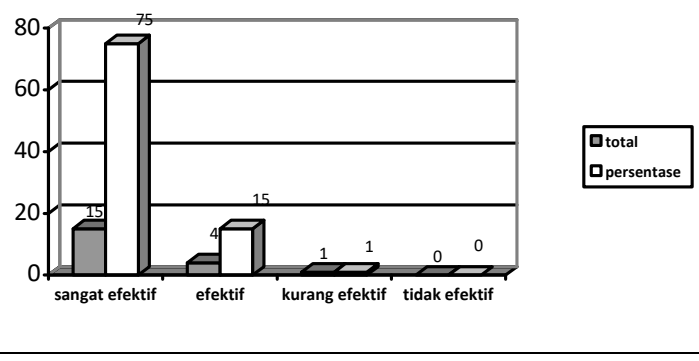

Gambar 5 Grafik Analisis Nilai Hasil Belajar Praktik

\section{Pembahasan Analisis Hasil Belajar Praktik menggunakan Metode Syndicate Group Discussion}

Berdasarkan analisis hasil belajar praktik menggunakan metode syndicate group discussion pada praktik pembuatan busana wanita (TPBW) menunjukkan bahwa 63,66 \% dalam kategori sangat efektif, sebanyak 33,17\% dalam kategori efektif, sebanyak 2,17\% dalam kategori Kurang efektif dan $1,00 \%$ dalam kategori tidak efektif. Maka dapat dideskripsikan Berdasarkan analisis hasil belajar praktik menggunakan metode syndicate group discussion pada praktik pembuatan busana wanita $(T P B W)$ menunjukkan kategori sangat efektif. Hasil analisis lebih lanjut juga menunjukkan bahwa analisis hasil belajar menggunakan syndicate group discussion pada beberapa aspek, yaitu aspek kognitif, aspek afektif dan aspek psikomotor semuanya menunjukkan kategori sangat efektif, masing-masing aspek sebesar 68,33\% pada aspek kognitif, 63,50\% pada aspek afektif dan $61,15 \%$ pada aspek psikomotor. Hal ini relevan dengan pendapat Notoatmodjo (2007) bahwa Faktor yang mempengaruhi pengetahuan dalam diri seseorang adalah: (1) pendidikan, (2) informasi, (3) sosial budaya dan ekonomi, (4) lingkungan, (5) pengalaman dan (6) usia. Pembelajaran menggunakan metode syndicate group discussion yang dilakukan sebelum praktikum merupakan pendidikan, informasi dan pengalaman yang diperoleh siswa sebelum melaksanakan praktik., sehingga hal-hal yang akan terjadi dalam praktik seperti kesalahan-kesalahan dalam proses praktik dapat diminimalisir. Hal ini juga senada dengan pendapat Leighbody dan Kidd, (1966:21) bahwa Pada pengajaran praktik terdapat 4 tahapan yang harus dikuasai yaitu (1) tahap persiapan, (2) tahap presentasi, (3) tahap aplikasi, dan (4) tahap pengujian. Keempat tahapan esensial tersebut haruslah dilaksanakan oleh guru dengan melibatkan siswa secara bersama-sama mulai dari awal sampai akhir pembelajaran praktik.

Sedangkan nilai hasil belajar pada mata kuliah praktik TPBW menggambarkan 75,00\% menggambarkan nilainya sangat memuaskan, $20 \%$ memuaskan dan 5,00\% kurang memuaskan. Ini dapat diungkapkan bahwa capaian nilai pada mata kuliah praktik TPBW telah dapat menunjukkan nilai dalamkategori sangat memuaskan yaitu nilai dalam rentangan A, A- dan B+. Nilai Praktik ini adalah nilai yang secara utuh termasuk aspek kognitif, afektif dan psikomotor. Hal ini sesuai dengan pendapat Sudijono (2012:32) bahwa belajar praktik mampu mengungkapkan hasil belajar yang dapat mengungkap aspek proses berpikir (cognitive domain) juga dapat meng Hungkap aspek kejiwaan lainnya, yaitu aspek nilai atau sikap (affective domain) dan aspek keterampilan (psychomotor domain) yang melekat pada diri setiap individu peserta didik. Hasil penelitian Wahyono, 2009 ian menunjukkan metode pembelajaran syndicate group efektif dalam meningkatkan kualitas pembelajaran.

\section{Kesimpulan}

Kesimpulan dari hasil penelitian yang berjudul Analisis Hasil Belajar Praktik Pembuatan Busana Wanita Menggunakan Syndicate Group Discussion adalah: 1) Syndicate Group Discussion sebagai metode diskusi yang dilaksanakan sebelum praktik memberikan kontribusi positif baik dari aspek kognitif, afekti dan psikomotor masing masing sebesar $68,33 \%$ pada aspek kognitif, 63,50\% pada aspek afektif dan $61,15 \%$ pada aspek psikomotor pada pembelajaran praktik pembuatan busana wanita, 2) Nilai Hasil belajar praktik pembuatan busana wanita menunjukkan kategori sangat memuaskan sebesar $75 \%$, memuaskan $20 \%$ dan sisanya $5 \%$ kurang memuaskan. Artinya Syndicate Group Discussion yang diterapkan pada praktik pembuatan busana wanita memberikan kontribusi capaian hasil akhir praktik.

Saran dalam penelitian ini sebaiknya metode Syndicate Group Discussion tidak hanya digunakan diawal praktik saja akan tetapi juga diakhir praktik agar mahasiswa praktikan dapat menganalisis hasil praktiknya yang memungkinkan siswa untuk dapat menganalisis hasil praktik. Hal ini sangat bermanfaat agar pada praktik selanjutnya memiliki pengalaman yang mendalam secara positif sehingga memberikan hasil praktik yang lebih baik lagi.

\section{Ucapan Terima Kasih}

Atas terselesaikannya artikel dalam penelitian ini dan terlaksananya penelitian ini kami mengucapkan terimakasih kepada: 
1. Dr. H. Andoko MT, selaku Dekan FT yang telah mengapresiasi dosen untuk melaksanakan penelitian sesuai bidang keahliannya.

2. Dr. Hary Suswanto, S.T, M.T selaku Wakil Dekan II bidang keuangan dan sarana prasarana yang telah merealisasikan anggaran guna penelitian sehingga mendorong untuk mewujudkan Karya ilmiah ini,

3. Annisau Nafiah S.Pd, M.Pd yang telah membantu dalam pelaksanaan penelitian ini

4. Seluruh anggota Tim yang terlibat dalam penelitian ini Dra. Nurul Aini, M.Pd, Dra Nur Endah Purwaningsih, M.Pd, Riski Rahayuningtyas, dan Jihan Amalia. Terimakasih atas kerjasamanya.

\section{Daftar Pustaka}

Dimyati dan Mudjiono. (2002). Belajar dan Pembelajaran. Jakarta: Rineka Cipta dan Depdikbud.

Istiarni. (2015). Pengaruh Penerapan Metode Pembelajaran Syndicate group discussion discussion terhadap Pemahaman Konsep Matematika Siswa SMA Negeri 14 Pekanbaru. Suska Journal of Mathematics Education Vol.1, No.1, 2015. Halaman 1927.http://download.portal garuda. org/ arti cle. php. diakses 26 april 2016.

Katalog Jurusan Teknologi Industri. (2015). Universitas Negeri Malang: Fakultas Teknik.

Leighbody, G.B., \& Kidd, D.M. (1968). Methods of teaching shop and technical subjects. New York: Delmar Publisher.

Notoatmojo, Soekidjo, (2007).Promosi Kesehatan dan Ilmu Perilaku. Rineka Cipta. Jakarta

Purwanto. (2010). Evaluasi Hasil Belajar. Yogyakarta: Pustaka Belajar.

Slameto. (2010). Belajar dan Faktor-Faktor yang mempengaruhinya. Jakarta: Rineka Cipta

Slameto. (2010). Belajar dan Faktor-Faktor yang mempengaruhinya. Jakarta: Rineka Cipta

Sudjana, Nana. (2009). Dasar dasar Proses Belajar Mengajar. Bandung: Sinar Baru

Wahyono. (2009). Penerapan Metode Diskusi Syndicate Group Untuk Meningkatkan pemahaman Mahasiswapada Konsep Dasar Pengantar Ilmu Ekonomi . Jurnal Pendidikan Ekonomi Vol 4 No.1 Juli, Tahun 2009 http://download.portal garuda. org/. Diakses 17 Mei 2016. 